Check for updates

Cite this: RSC Adv., 2020, 10, 7301

Received 18th December 2019

Accepted 4th February 2020

DOI: 10.1039/c9ra10683a

rsc.li/rsc-advances

\section{Spindle-like MRI-active europium-doped iron oxide nanoparticles with shape-induced cytotoxicity from simple and facile ferrihydrite crystallization procedure $\uparrow$}

\author{
Afanasy V. Lunin, ${ }^{a}$ Ilya L. Sokolov, ${ }^{a}$ Ivan V. Zelepukin, (D) ab Ilya V. Zubarev, ${ }^{a}$ \\ Maria N. Yakovtseva, ${ }^{a}$ Elizaveta N. Mochalova, ${ }^{\text {ac }}$ Julian M. Rozenberg, ${ }^{a}$ \\ Maxim P. Nikitin ${ }^{a}$ and Eugene L. Kolychev (D)*ac
}

\begin{abstract}
Nanoparticles (NPs) that can provide additional functionality to the nanoagents derived from them, e.g., cytotoxicity or imaging abilities, are in high demand in modern nanotechnology. Here, we report new spindle-like iron oxide nanoparticles doped with $\mathrm{Eu}^{3+}$ that feature magnetic resonance imaging (MRI) contrasting properties together with shape-related cytotoxicity (unusual for such low $2.4 \%$ Eu content). The NPs were prepared by a novel procedure for doping of iron oxide nanoparticles based on the crystallization of amorphous ferrihydrite in the presence of hydrated europium(II) oxide and were thoroughly characterized. Cytotoxicity of low Eu-doped spindle-like hematite nanoparticles was confirmed by MTT assay and further studied in detail by imaging flow cytometry, optical and electron microscopies. Additionally, enhancement of MRI contrast properties of NPs upon doping with europium was demonstrated. According to the MRI using mice as an animal model and direct inductively coupled plasma mass spectrometry (ICP-MS) ${ }^{153} \mathrm{Eu}$ biodistribution measurements, these particles accumulate in the liver and spleen. Therefore, NPs present a novel example of a multimodal component combining magnetic imaging and therapeutic (cytotoxic) abilities for development of theranostic nanoagents.
\end{abstract}

\section{Introduction}

One of the rapidly developing applications of nanostructured materials is the construction of nanoagents capable of detection and selective elimination of pathogens including bacterial infections and cancer cells. ${ }^{1-4,56}$ Such agents are usually constructed using a nanoparticle as a base. This particle may have no function but bearing surface-modified layers of reagents for selective detection, imaging, and killing pathogen cells. ${ }^{5}$ Therefore, the nanoparticle plays the role of an inert carrier. Meanwhile, the nanoparticles (NPs) can bring some functionality to the nanoagents, e.g., capability of optical or magnetic detection, or be cytotoxic on their own. ${ }^{6}$ In the latter case, the surface modification can be aimed only at the targeted delivery of the particle and does not require a more complex modification for binding of cytotoxic agents. Moreover, the design of

${ }^{a}$ Moscow Institute of Physics and Technology (National Research University), 9 Institutskiy per., Dolgoprudny, Moscow, 141700, Russia

${ }^{b}$ Shemyakin-Ovchinnikov Institute of Bioorganic Chemistry, Russian Academy of Sciences, Ulitsa Miklukho-Maklaya, 16/10, Moscow, 117997, Russia

${ }^{c}$ Prokhorov General Physics Institute of the Russian Academy of Sciences, 38 Ulitsa Vavilova St., Moscow 119991, Russia. E-mail: eugene.kolychev@gmail.com

$\dagger$ Electronic supplementary information (ESI) available. See DOI: 10.1039/c9ra10683a nanoagents may be more convenient if the nanosized core combines the imaging and therapeutic functions. An attractive way for facile preparation of the multifunctional nanoparticles of this type is doping them with an agent bringing an additional modality. Such modifications mostly require a small amount of doping reagent, which provides alteration of the original properties of undoped nanoparticles. ${ }^{7-10}$

For example, doping of NPs with europium can provide a number of functionalities: (i) allow precise highly-sensitive detection of the particles ex vivo with inductively coupled plasma mass spectrometry (ICP-MS) due to absence of this metal in mammal tissues; (ii) make NPs fluorescent, which is highly useful for visualization NPs ex vivo and in vivo; (iii) enhance MRI-contrasting properties of the NPs.

Iron oxide nanoparticles are widely used to design biocompatible nanoagents, which additionally could be used as contrast agents for MRI imaging. ${ }^{11-13}$ The NPs of hydrous ferric oxides such as goethite and hematite have a large specific surface area; the surface is hydrophilic and can be modified by adsorbing various cations and anions, which can introduce a novel functionality to the particles ${ }^{14-17}$ However, the adsorption of the metal ions by these particles is usually a reversible process. Therefore, the metal ions can easily leak into the solution from the surface of the nanoparticles. ${ }^{18-21}$ 
Recently, we reported on the synthesis of well-defined crystalline hydrous ferric oxide particles obtained by acid-mediated crystallization of ferrihydrite. ${ }^{22}$ Crystallization of ferrihydrite together with another amorphous metal oxide may produce the nanoparticles, in which the dopant is fairly distributed not only on the surface but also throughout the whole volume of the nanocrystal. Such nanoparticles would not lose the doping ion even if their surface is dissolved or destroyed.

Here, we report on the novel synthesis of spindle-like iron oxide nanoparticles doped with $\mathrm{Eu}^{3+}$ by crystallization of ferrihydrite in the presence of hydrated europium oxide, and preliminary investigation of their cytotoxic and MRI contrasting properties. Moreover, the presented data have shown that the toxicity is the result of not only heavy metal content but also a combination of shape and europium doping.

\section{Experimental}

\section{Starting materials}

Sigma-Aldrich (USA): $\mathrm{FeCl}_{3} \cdot 6 \mathrm{H}_{2} \mathrm{O}(>99 \%), \mathrm{CaCl}_{2} \cdot 6 \mathrm{H}_{2} \mathrm{O}(>98 \%)$, carboxymethyl-dextran sodium salt (CMD, $>90 \%$, cat. 86524100G-F), fluorescein isothiocyanate isomer I (FITC, >90\%), paraformaldehyde (95.0-100.5\%), glutaraldehyde (grade I), sodium cacodylate trihydrate (BioXtra, >98\%), osmium tetroxide (>99\%), PBS (>99\%) and HEPES (>99.5\%) buffers; Alfa Aesar (Germany): $\mathrm{EuCl}_{3} \cdot 6 \mathrm{H}_{2} \mathrm{O}(>99.99 \%)$; Biotium (USA): propidium iodide (PI) (>95\%); BioLegend (USA): Purified Annexin V (cat. 640901); Dia-M (Russian Federation): nitric acid (70\%, w/ w), methylthiazolyldiphenyl-tetrazolium bromide (MTT, $>98.5 \%$ ), aqueous ammonia (25\%,w/w); AppliChem (Germany): Triton X-100 (Molecular biology grade); Rushim (Russian Federation): dimethyl sulfoxide (DMSO, 98\%). All commercially available reagents were used as received. Saline solution was of medicine grade. Milli-Q water (Merck Millipore, USA) was used in the preparation of aqueous solutions.

\section{NPs synthesis}

The different volumes of $0.3 \mathrm{M}$ aqueous solution of $\mathrm{EuCl}_{3}(0 \mu \mathrm{L}$, $50 \mu \mathrm{L}, 100 \mu \mathrm{L}$, and $200 \mu \mathrm{L}$ ) were added to $1 \mathrm{~mL}$ of $0.3 \mathrm{M}$ aqueous solution of $\mathrm{FeCl}_{3}$. The resulting mixtures were treated with $125 \mu \mathrm{L}$ of $25 \%$ aqueous ammonia and homogenized in Vortex, followed by incubation at $90{ }^{\circ} \mathrm{C}$ for $2 \mathrm{~h}$. After the reaction was complete, the precipitate was washed by centrifugation and mixed with 1.0 $\mathrm{mL} \mathrm{0.6} \mathrm{M} \mathrm{nitric} \mathrm{acid.} \mathrm{The} \mathrm{resulting} \mathrm{mixture} \mathrm{was} \mathrm{stirred}$ overnight at room temperature and carefully washed with Milli-Q water. CMD coating was performed as follows: $150 \mu \mathrm{L}$ of NPs with a concentration of $35 \mathrm{~g} \mathrm{~L}^{-1}$ were mixed with $150 \mu \mathrm{L}$ of $10 \%(\mathrm{w} / \mathrm{v})$ aqueous solution of $\mathrm{CMD}$, incubated overnight at $90{ }^{\circ} \mathrm{C}$ and washed 2 times by centrifugation with Milli-Q water.

\section{NPs characterization}

The particle hydrodynamic diameters were determined using a Photocor Complex (Photocor Ltd., Russia). All the measurements were performed in Milli-Q water at room temperature. Scanning electron microscopy images of NPs were obtained with a Tescan MAIA3 microscope (Tescan, Czech Republic) at an accelerating voltage of $10 \mathrm{kV}$. The samples were diluted down to appropriate concentrations, placed onto a silicon wafer and then air-dried. $\zeta$-potential of the nanoparticles was measured by electrophoretic light scattering using a Zetasizer Nano ZS (Malvern Instruments, UK). The measurements were performed in $10 \mathrm{mM} \mathrm{NaCl}$ solution at room temperature. FTIR spectra were collected with a Nicolet iS50 Spectrometer (Thermo Fisher Scientific, USA). The nanoparticle suspensions were air-dried at $60{ }^{\circ} \mathrm{C}$. Raman spectra were measured with a Confotec MR 350 Raman laser scanning confocal microscope (Sol instruments, Belarus) at a $100 \times$ magnification. The nanoparticle suspension was dropped onto a borosilicate glass coverslip and air-dried. A $633 \mathrm{~nm}$ laser $(40 \mathrm{~mW})$ was used for excitation. X-ray diffraction (XRD) patterns were collected with a Rigaku diffractometer with $\mathrm{CuK} \alpha$ radiation (SmartLab, Japan). The nanoparticle suspensions were air-dried at $60^{\circ} \mathrm{C}$. Transmission electron microscopy energy-dispersive X-ray (TEM-EDX) analysis was performed on a $200 \mathrm{kV}$ JEOL JEM 2100 TEM (Tokyo, Japan). Relaxivities were calculated using relaxation times (water solution, RT), measured on a 0.23 T Minispec Analyzer MQ10 (Bruker, USA). Magnetization measurements were performed on a vibrating sample magnetometer VSM 7410 (Lake Shore Cryotronics, USA).

\section{Animals}

Male C57BL/6 mice of 27-32 g weight were used for experiments. All procedures were carried out in compliance with the National Institutes of Health (NIH) Guide for the Care and Use of Laboratory Animals and were approved by the Institutional Animal Care and Use Committee of Shemyakin-Ovchinnikov Institute of Bioorganic Chemistry.

\section{Magnetic resonance imaging}

A mouse was injected with $1 \mathrm{mg}$ of NPs in $100 \mu \mathrm{L}$ of $150 \mathrm{mM}$ $\mathrm{NaCl}$. After $3 \mathrm{~h}$, the animal was sacrificed by $\mathrm{CO}_{2}$ inhalation, and magnetic resonance imaging (MRI) was immediately performed using an ICON 1T MRI system (Bruker, USA) with the mouse whole-body volume RF coil. The following common parameters were used for the sequences: for the RARE sequences: $\mathrm{RARE}$ factor $=1$, TR $=3000 \mathrm{~ms}$, TE $=40 \mathrm{~ms}$, resolution of $156 \mu \mathrm{m}, \mathrm{FOV}=80 \times 30 \mathrm{~mm}, 4$ slices per scan, slice thickness of $1 \mathrm{~mm}$; for the FLASH sequences: flip angle $=30^{\circ}$, $\mathrm{TR}=300 \mathrm{~ms}, \mathrm{TE}=10 \mathrm{~ms}$, resolution of $156 \mu \mathrm{m}, \mathrm{FOV}=80 \times 30$ $\mathrm{mm}, 4$ slices per scan, slice thickness of $1 \mathrm{~mm}$.

\section{ICP-MS analysis}

Inductively coupled plasma mass spectrometry (ICP-MS) measurements were performed using a NexION 2000 (PerkinElmer, USA) mass spectrometer. Mouse organs were collected immediately after the MRI measurements. Each organ was weighed and digested with 4 parts of concentrated nitric acid for $15 \mathrm{~min}$ at $65{ }^{\circ} \mathrm{C}$. The nanoparticles were also dissolved in concentrated nitric acid. The mixtures were diluted 10 times with water and used for the measurements. ${ }^{153}$ Eu peak was used for analysis. To calculate the share of NPs in an organ, we used Formula S1. $\dagger$ 


\section{MTT assay}

For the cell viability MTT test, Chinese hamster ovary (CHO) cells were seeded in $10 \%$ fetal bovine serum in Dulbecco's Modified Medium/F12 $24 \mathrm{~h}$ before the experiment. 1000 cells per well were incubated for $24 \mathrm{~h}, 48 \mathrm{~h}$, and $72 \mathrm{~h}$ in $200 \mu \mathrm{L}$ of the medium with NPs in the following concentrations: $500,160,50,16,5$, and $0 \mu \mathrm{g}$ $\mathrm{mL}^{-1}$. After that, the medium was replaced by $100 \mu \mathrm{L}$ of $0.5 \mathrm{mg}$ $\mathrm{mL}^{-1}$ MTT solution in the media and incubated for $30 \mathrm{~min}$ to form formazan crystals. Then, the medium was removed, and the samples were homogenized in $100 \mu \mathrm{L}$ of dimethyl sulfoxide. The samples were transferred to a different plate, and the solution absorption was measured by a spectrophotometer at $570 \mathrm{~nm}$.

\section{SEM of CHO cells}

Cell cultures for scanning electron microscopy (SEM) were cultured on a cover glass prior to the formation of a monolayer. The cells were fixed in $2 \%$ paraformaldehyde and $2.5 \%$ glutaraldehyde in cacodylate buffer $(0.1 \mathrm{M}, \mathrm{pH} 7.2$, according to Karnovsky) with $5 \%$ sucrose, and then postfixed in $2 \%$ osmium tetroxide water solution. The material was dehydrated in alcohol and acetone, and dried at a critical point in a K850 Critical Point Dryer (Quorum Technologies, UK). A $15 \mathrm{~nm}$ gold/ palladium layer was deposited onto the surface of the samples in a Q150T Plus metal sputtering device (Quorum Technologies, UK). The cells were studied in an AURIGA FIB-SEM workstation scanning electron microscope (Carl Zeiss \& MT, Germany) with a $\mathrm{SE}$ detector in the 50-50 000 magnification range.

\section{Imaging flow cytometry}

Purified Annexin V was labeled with FITC according to the manufacturer's protocol in 1:60 molar concentration ratio of Annexin $\mathrm{V}$ : FITC. The CHO cells (30 000 per well) were seeded onto 6-well plates and cultured overnight, followed by incubation with $50 \mu \mathrm{g}$ $\mathrm{mL}^{-1}$ NPs in $10 \%$ fetal bovine serum in Dulbecco's Modified Medium/F12. Then, the cells from each well were harvested and resuspended in $50 \mu \mathrm{L}$ of annexin $\mathrm{V}$ binding buffer (10 mM HEPES $\mathrm{pH}$ 7.4, $140 \mathrm{mM} \mathrm{NaCl}$, and $2.5 \mathrm{mM} \mathrm{CaCl}_{2}$ solution). After $10 \mathrm{~min}$ incubation with $0.5 \mu \mathrm{g} \mathrm{mL}{ }^{-1}$ Annexin V-FITC in PBS and followed 5 min incubation with $0.25 \mu \mathrm{g} \mathrm{mL} L^{-1}$ PI in PBS, the cells were

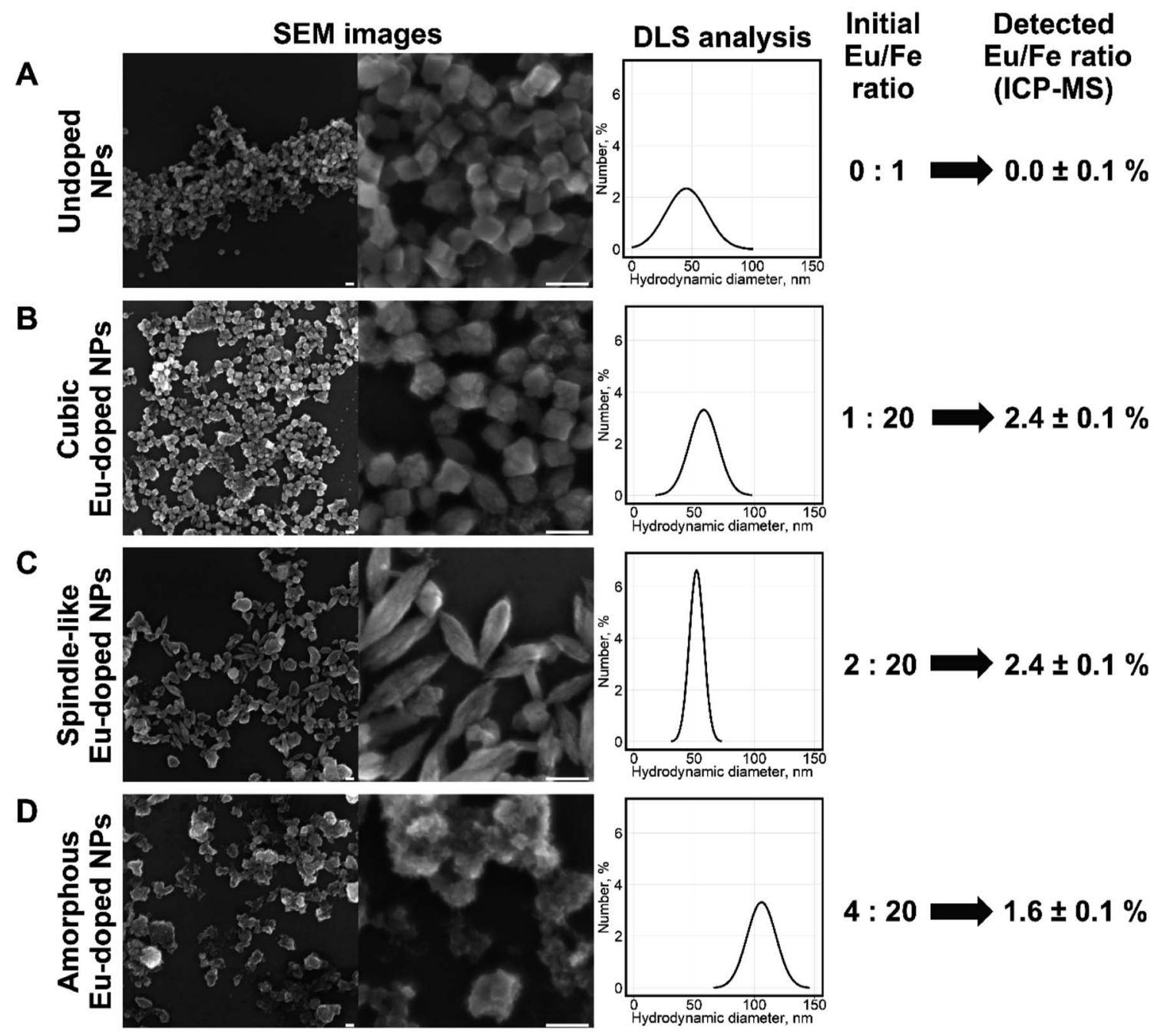

Fig. 1 Analysis of nanoparticles prepared from mixtures of iron(III) chloride with different amounts of europium(III) chloride: row A: no europium, row $\mathrm{B}$ : Eu/Fe molar ratio $=1: 20$, row $\mathrm{C}$ : Eu/Fe molar ratio $=1: 10$, row D: Eu/Fe molar ratio $=1: 5$. Two left images in each row show SEM images, scale bar is $100 \mathrm{~nm}$; the plot and scheme in each row show results of DLS and elemental analyses, respectively. 

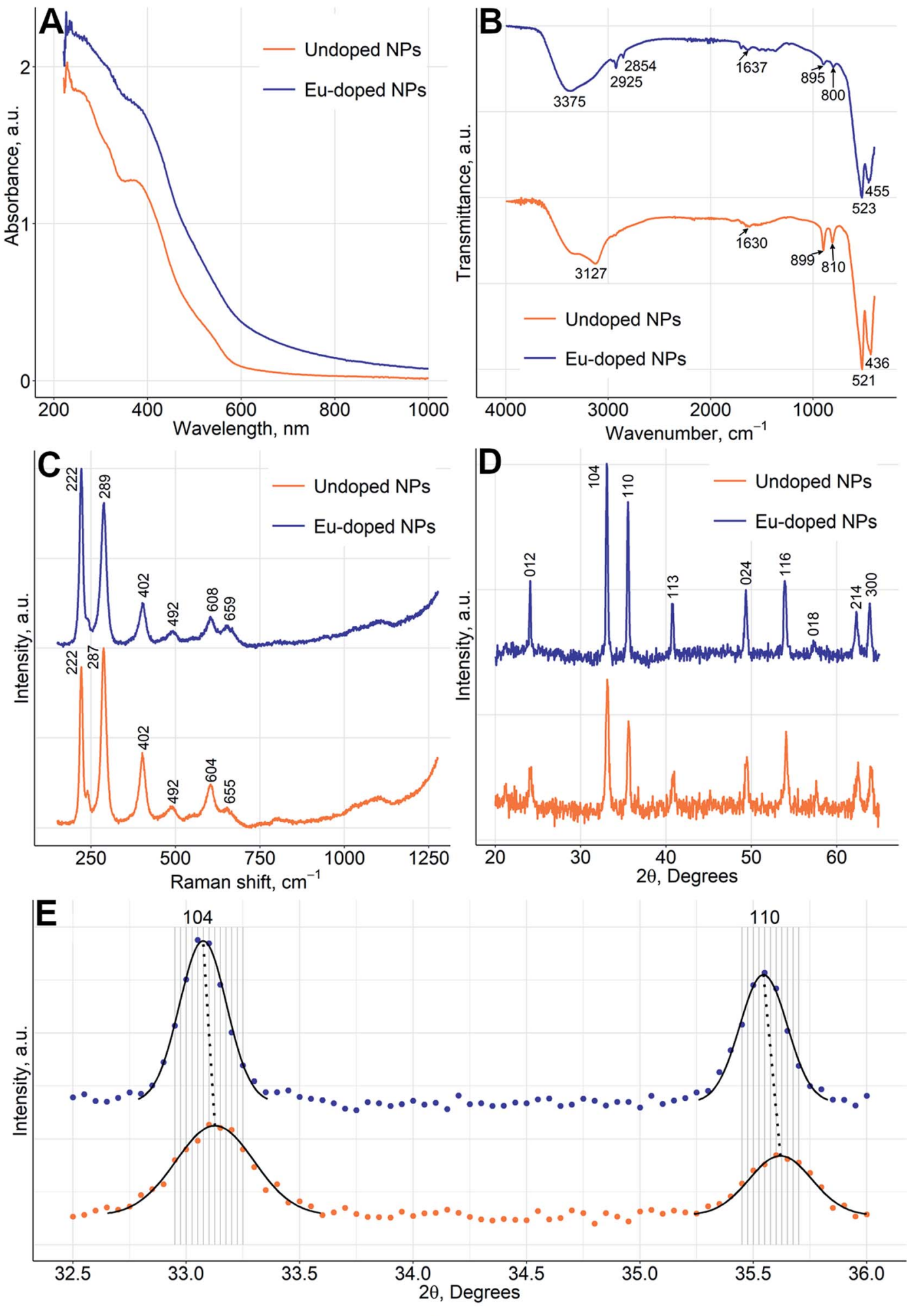

$\sim$ Eu-doped NPs $\approx$ Undoped NPs

Fig. 2 Characterization of the physical properties of the undoped NPs and the spindle-like europium-doped NPs: (A) UV/Vis absorption spectra; (B) FTIR transmittance spectra. Characteristic absorption bands are indicated by arrows; (C) Raman spectra with marked positions of peaks; (D)

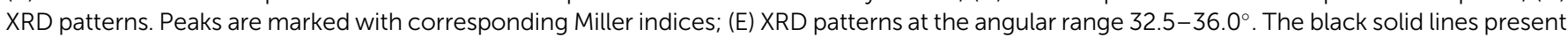
Gaussian peak approximation, the black dotted lines link corresponding peaks maxima. 
immediately processed with an imaging flow cytometer ImageStream X Mark II (Luminex Corporation, USA) using a 40× objective, $488 \mathrm{~nm}$ laser $(50 \mathrm{~mW})$ for excitation of fluorescence and $785 \mathrm{~nm}$ laser $(0.2 \mathrm{~mW})$ for side scatter measurements. We gated focused single cells, 1500 events were collected for each sample. For the obtained data, the compensation was applied.

\section{Optical microscopy}

The CHO cells were seeded in imaging dishes (30 000 cells per dish) with coverslip bottom and were incubated overnight in $1.9 \mathrm{~mL}$ of $10 \%$ fetal bovine serum in Dulbecco's Modified Medium/F12 at $37{ }^{\circ} \mathrm{C}$. Then $100 \mu \mathrm{L}$ of NPs suspension were added to reach the final NPs concentration of $50 \mu \mathrm{g} \mathrm{mL}{ }^{-1}$. After that, the dishes were incubated for $48 \mathrm{~h}$. Finally, $0.75 \mu \mathrm{L}$ of Hoechst ( $10 \mathrm{~g} \mathrm{~L}^{-1}$ in PBS) and $5 \mu \mathrm{L}$ PI (50 $\mathrm{mg} \mathrm{L}^{-1}$ in PBS) were added, and the cells were stained for $10 \mathrm{~min}$.

All microscopy images were acquired with a FLUOVIEW FV3000 confocal laser scanning microscope (Olympus Corporation, Japan) using an $\times 40$ objective. For fluorescent imaging, $405 \mathrm{~nm}(0.75 \mathrm{~mW})$ and $561 \mathrm{~nm}(0.4 \mathrm{~mW})$ lasers, and cooled GaAsP photomultipliers as detectors were used. To produce differential interference contrast (DIC) images, a MicroPublisher 5.0 RTV camera (Teledyne QImaging, Canada) was used.

\section{Absorbance measurements}

The absorbance measurements were recorded with a ClarioStar microplate reader (BMG LABTECH, Germany) using polystyrene 96-well plates. For UV/Vis spectrum recording, UV-transparent 384-well plates were used.

\section{Nanoparticle sterilization}

For all in vitro experiments, NPs were sterilized via autoclaving for $20 \mathrm{~min}$ at $121^{\circ} \mathrm{C}$ in Dulbecco's Modified Medium/F12 (without serum).

\section{Biochemical serum assay}

All the assays were performed using commercial kits. ALT 360 and BIL $100 \mathrm{~S}$ were purchased from BIO-LACHEMA-TEST, Czech Republic; LDH-2-OLVEX, AST-RF-OLVEX, and CREATININE-DOLVEX were purchased from Olvex Diagnosticum, Russian Federation. All the assays were used according to the instructions. To examine mice samples, quantities of the reagents were scaled proportionally.

\section{Results and discussion}

The NPs were prepared by the modified procedure described recently. ${ }^{22}$ Briefly, mixtures of iron(III) and europium(III) chlorides were precipitated using aqueous ammonia. The precipitate was resuspended in $\mathrm{HNO}_{3}$ and stirred overnight. The resulting NPs containing different amounts of europium were analyzed by scanning electron microscopy (SEM), inductively coupled plasma mass spectrometry (ICP-MS), and dynamic light scattering (DLS). According to SEM (Fig. 1) the morphology of the nanoparticles changed from cubic to less-defined cubic at the $\mathrm{Eu} / \mathrm{Fe}$ molar ratio of $1: 20$ in the reaction mixture to well-

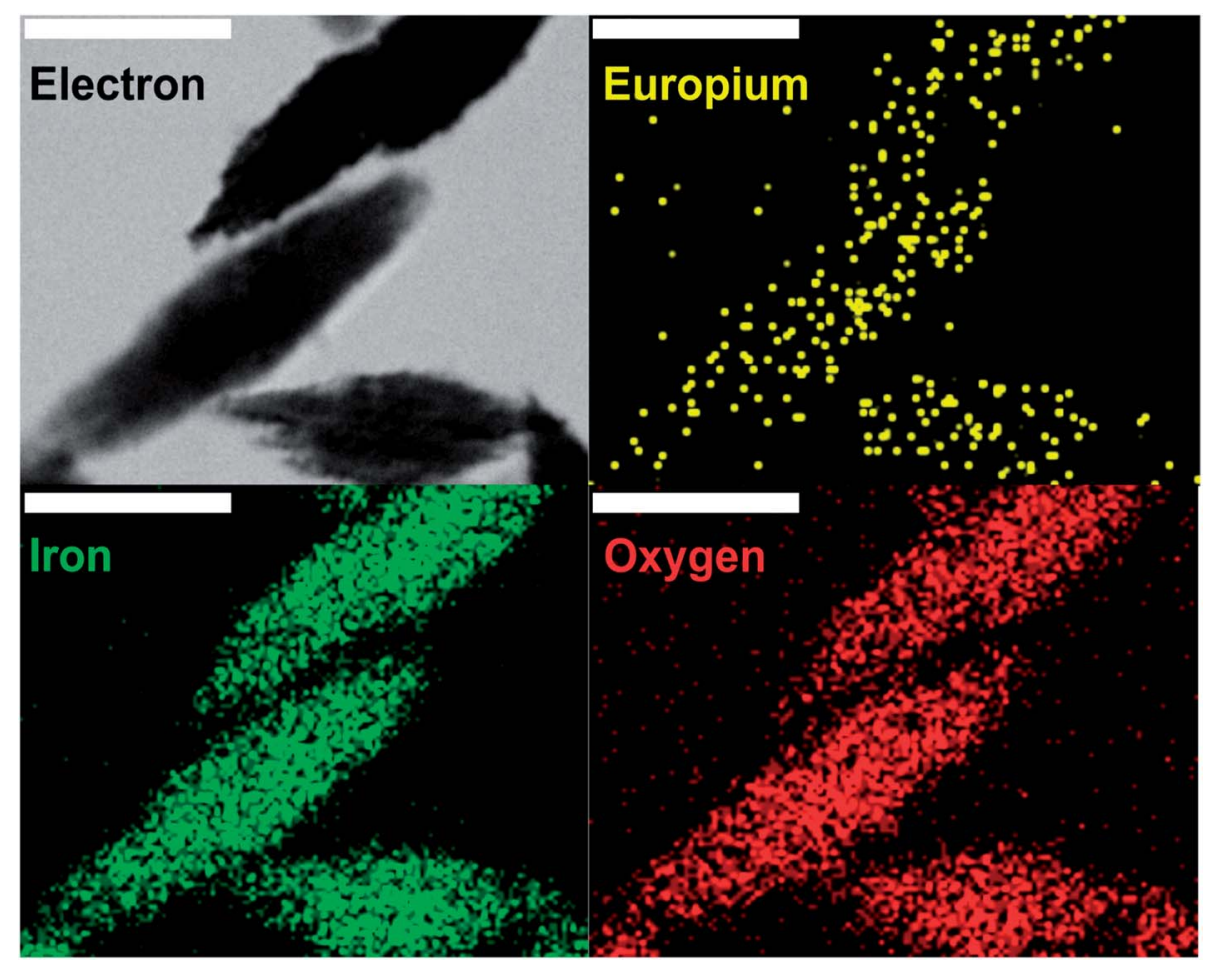

Fig. 3 TEM-EDX mapping analysis of spindle-like europium-doped NPs. The data were collected for iron and oxygen (K series) and europium (L series). The scale bar is $100 \mathrm{~nm}$. 
defined spindle-like particles at the Eu/Fe molar ratio of $1: 10$, which is in agreement with the data previously obtained for the hydrothermal synthesis of Gd-doped iron oxide particles. ${ }^{23}$

Further increase in europium concentration (Eu/Fe molar ratio $1: 5$ ) led to the formation of poorly defined amorphous particles. The DLS analysis showed a slight increase in hydrodynamic diameter from $44 \pm 18$ to $58 \pm 12$ and $52 \pm 6 \mathrm{~nm}$ at the $\mathrm{Eu} / \mathrm{Fe}$ molar ratios of $1: 20$ and $1: 10$, respectively. Whereas the amorphous particles size drastically increased to $106 \pm 12 \mathrm{~nm}$. The ICP-MS analysis showed that europium content in NPs was lower than the amount of europium in the reaction mixture. The highest Eu/Fe molar ratio, which allowed obtaining welldefined uniform nanoparticles, was $1: 10$. Those NPs contained $2.4 \%$ europium and were studied in detail. They were used for further investigation of toxicity and MRI-contrasting properties. All the syntheses were carried out at least 10 times for each $\mathrm{Eu} / \mathrm{Fe}$ ratio to ensure reproducibility.

We believe that europium acts not only as a dopant but also as an inhibitor of the reaction. An increase of Eu/Fe molar ratio causes a decrease in the reaction yield; moreover, if the ratio is $1: 2$, the reaction does not occur. As a result, we suppose that an increased $\mathrm{Eu} / \mathrm{Fe}$ ratio enhances the europium doping ratio but may somehow interrupt the reaction. These facts explain the maximal doping ratio of $2.4 \%$ that is reached at different initial conditions. The effect of europium on the reaction is unclear and needs a detailed investigation.

The UV/Vis spectrum of NPs did not change significantly upon Eu doping (Fig. 1A), whereas the zeta potential of Eu-doped nanoparticles was negative $(-11 \pm 2 \mathrm{mV})$ in comparison to a positive value $(15 \pm 4 \mathrm{mV})$ for undoped iron oxide NPs. The change can be explained by a higher amount of nitrate anions coordinated to the surface of Eu-doped nanoparticles. That was also confirmed by spectroscopic Fourier Transform Infrared (FTIR) measurements (Fig. 1B) and in line with the more pronounced ability of europium to form anionic complexes with nitrate. ${ }^{24}$ As can be seen from the FTIR spectra of doped and undoped NPs, the amount of coordinated nitrate is higher in Eudoped nanoparticles. That can be judged from the peaks at 1637-
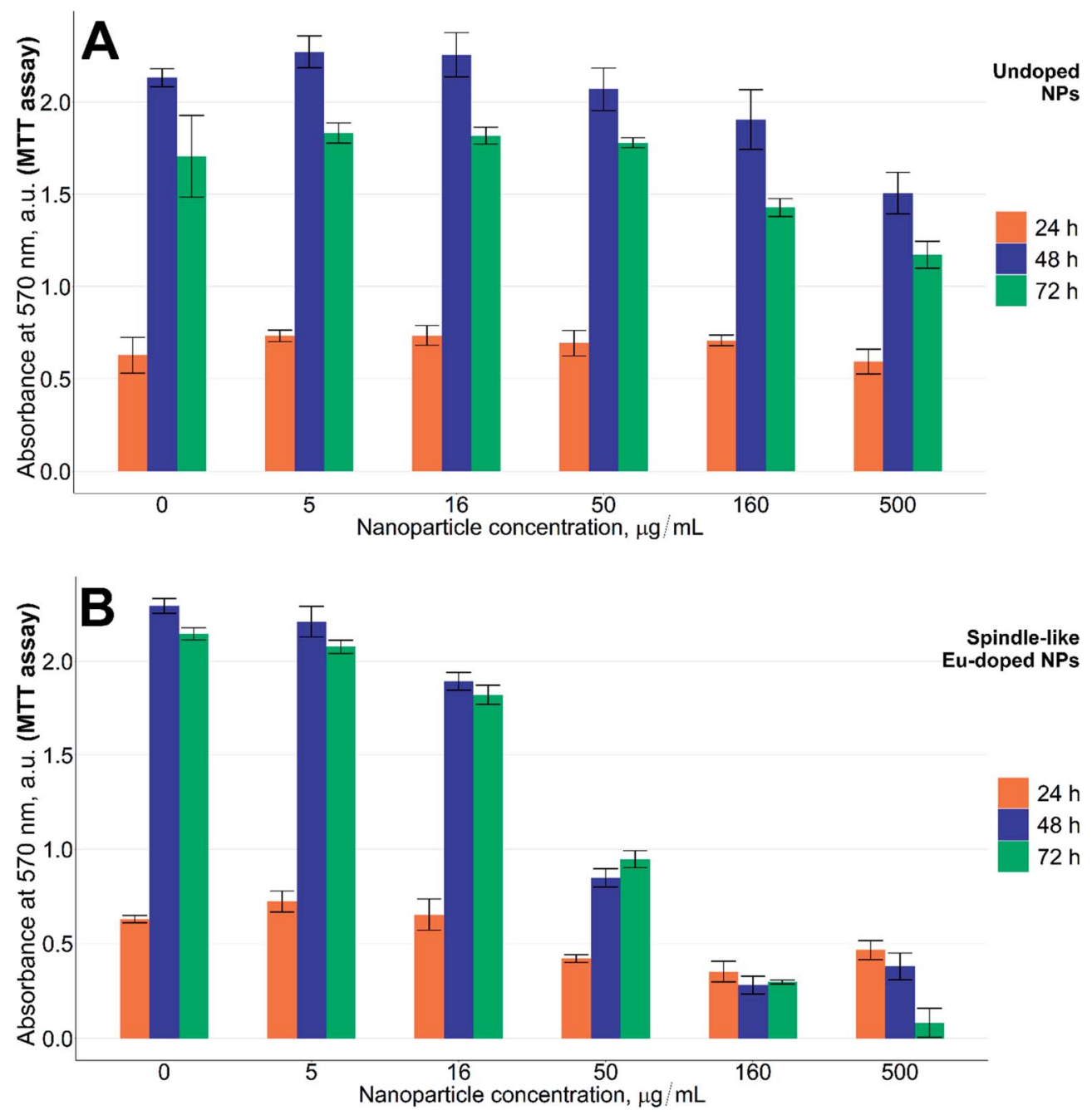

Fig. 4 MTT test results. (A) Undoped NPs; (B) spindle-like Eu-doped NPs. The nanoparticles were incubated with $\mathrm{CHO}$ cells for $24 \mathrm{~h}$ (orange bars), $48 \mathrm{~h}$ (blue bars), and $72 \mathrm{~h}$ (green bars). The positive control of cells death was $1 \%$ Triton X-100 solution in medium. The data are presented as mean \pm standard deviation ( $n=6$ per group). 
$1300 \mathrm{~cm}^{-1}, 2854$, and $2925 \mathrm{~cm}^{-1}$ (the similar peaks are also present in FTIR of pure europium nitrate [SDBS no. 40387]). Additionally, the spectra of both NPs samples contain two major peaks at 520 , and $440 \mathrm{~cm}^{-1}$, which are characteristic for hematite [RRUFF ID: R040024.1], as well as three minor peaks at 3200, 900, and $805 \mathrm{~cm}^{-1}$ characteristic for hydrated iron oxides, e.g., goethite [RRUFF ID: R050142.1]. The same results were obtained for the Raman spectra (Fig. 2C) of the NPs in comparison with the reported hematite spectrum, ${ }^{25}$ in which the peaks at 226, 292, 411,498 , and $612 \mathrm{~cm}^{-1}$ were similar to those at 222, 287, 402, $492,604 \mathrm{~cm}^{-1}$ for undoped NPs and 222, 289, 402, 492, $608 \mathrm{~cm}^{-1}$ for Eu-doped NPs. Finally, the powder X-ray diffraction (XRD) studies (Fig. 2D) confirmed that the XRD patterns of Eu-doped NPs were similar to those of undoped NPs, which were in turn identical to the XRD pattern of hematite (JCPDS file no. 33-0664). The shift of the pattern to lower angles were observed for the XRD
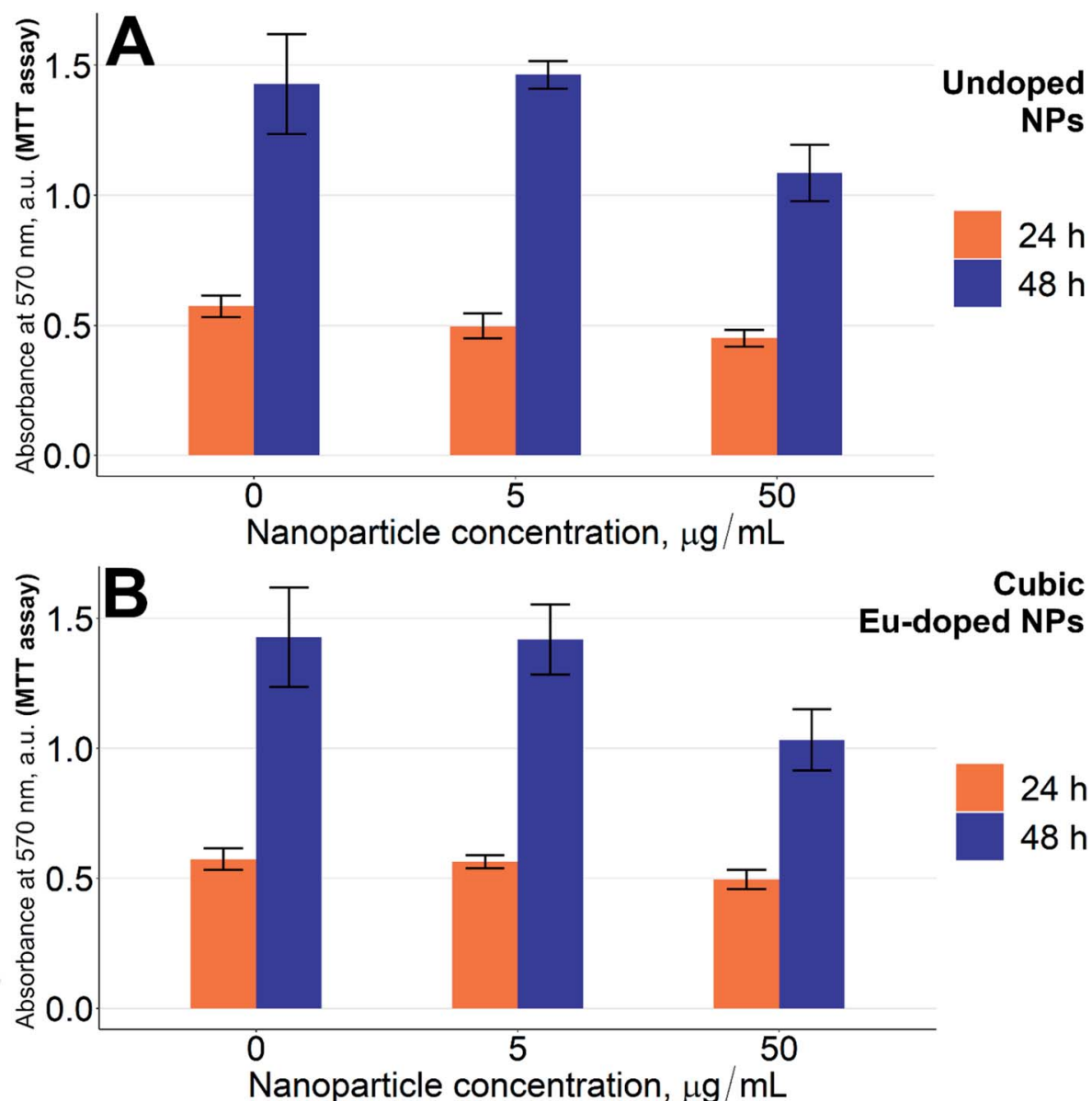

Cubic

Eu-doped NPs

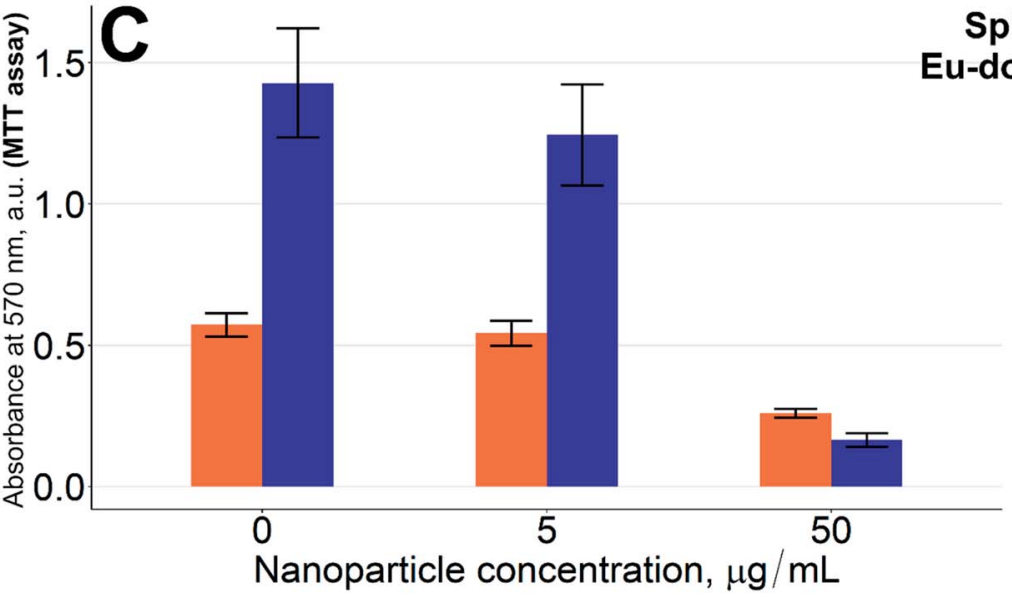

$24 \mathrm{~h}$

$48 \mathrm{~h}$

Fig. 5 MTT test results. (A) Undoped NPs; (B) cubic Eu-doped NPs; (C) spindle-like Eu-doped NPs. The nanoparticles were incubated with CHO cells for $24 \mathrm{~h}$ (orange bars), $48 \mathrm{~h}$ (blue bars). The positive control of cells death was $1 \%$ Triton $\mathrm{X}-100$ solution in medium. The data are presented as mean \pm standard deviation ( $n=6$ per group). 


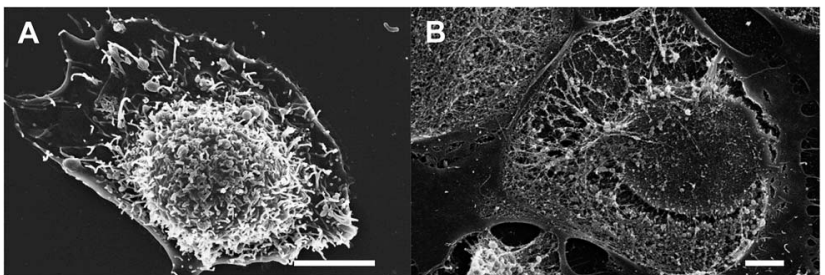

Fig. 6 SEM images of $\mathrm{CHO}$ cells. (A) An intact cell; (B) cell after treatment with spindle-like Eu-doped NPs with the destructed membrane. The scale bar is $2 \mu \mathrm{m}$.

pattern of the doped NPs. Therefore, the cell parameters (Fig. 2E) for the europium-doped NPs slightly increased from $a=5.038(2)$ $\AA, c=13.772(12) \AA$ in hematite to $a=5.050(1) \AA, c=13.7869(3) \AA$. The change in cell parameters confirms the homogeneous europium doping of NPs with formation of only one phase slightly different from hematite. In addition, the doped NPs were studied using TEM-EDX mapping analysis; the analysis showed uniform europium distribution (Fig. 3).

Standard MTT assay was used to evaluate how the europiumdoped iron oxide nanoparticles influenced cytotoxicity. ${ }^{26,27,57}$ As can be seen from Fig. 4, at concentrations above $50 \mu \mathrm{g} \mathrm{mL}^{-1}$ of the doped NPs, the CHO cells grow slower than the cells treated with undoped NPs at $24 \mathrm{~h}(p<0.05)$. The difference is more profound at $48 \mathrm{~h}$ or $72 \mathrm{~h}(p<0.001)$. Even at a concentration as high as $500 \mu \mathrm{g} \mathrm{mL}^{-1}$ of iron(III) oxide NPs without europium, the cells grew at nearly the same rate as control cells.

The origin of toxicity of NPs could be heavy metal content, as well as a particular shape of the NPs. It is worth to mention that the nanoparticles elongated along one axis are reported to be more cytotoxic because of a larger contact area with a cell membrane $\mathrm{e}^{28-30}$ and easier penetration of NPs through the cell membrane. ${ }^{31}$ A few reports on different europium-doped nanoparticles exist to date, however, most of them claim that the europium-doped nanoparticles show low to no toxicity and very good biocompatibility. ${ }^{32-39}$ A couple of publications report toxicity of the europium NPs at high concentrations and high content of europium. ${ }^{\mathbf{4 0 - 4 2}}$ Most studies describe that cell death from the Eu-contained NPs could be caused by accumulation of NPs in lysosomes followed by cell rupture and necrosis, ${ }^{43}$ by wrinkling of cells shape and shrinking the nuclei, ${ }^{44}$ by stopping cell proliferation through the down-regulation of the $\mathrm{Ca}^{2+}$ relying proteins, and by an increase in reactive oxygen species (ROS) concentration and mitochondrial damage. ${ }^{45}$

Since the low concentration of europium $(2.4 \%)$ could not alone induce severe cytotoxicity, the toxic effects of our NPs should be due to a combination of both factors, where the shape increases the toxicity of low levels of europium in NPs. To supplement the hypothesis on the shape-induced toxicity of the NPs, another MTT test was carried out using the lowest active concentrations of the spindle-like NPs $\left(50 \mu \mathrm{g} \mathrm{mL}{ }^{-1}\right)$ together with the cubic europium-doped NPs of the same europium content (that we show in Fig. 1B). Indeed, as can be seen from Fig. 5, the growth of cells in the presence of cubic europium-doped is similar to that of the cells treated with undoped iron oxide NPs (Fig. 5B and $\mathrm{A}$, respectively), whereas the growth of cells treated with spindle-like europium-doped NPs is slower $(p<0.01)$ (Fig. 5C).

Additional studies of the effect of the spindle-like NPs on CHO cells were carried out using microscopic techniques such
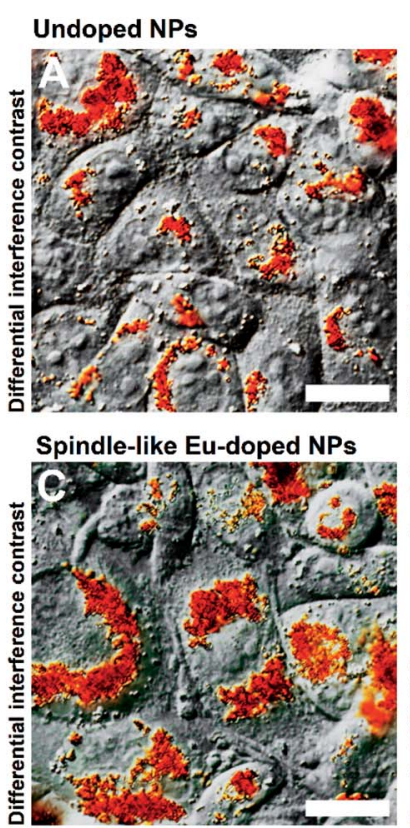

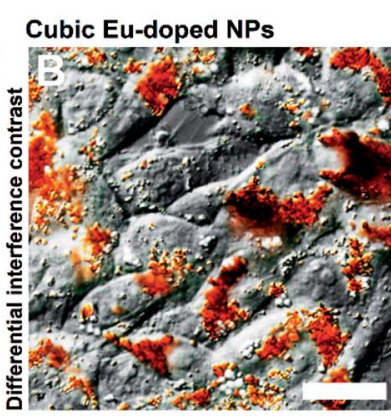

Spindle-like Eu-doped NPs

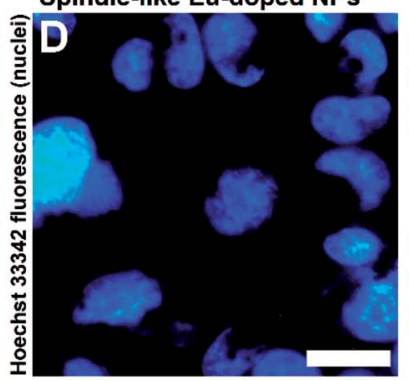

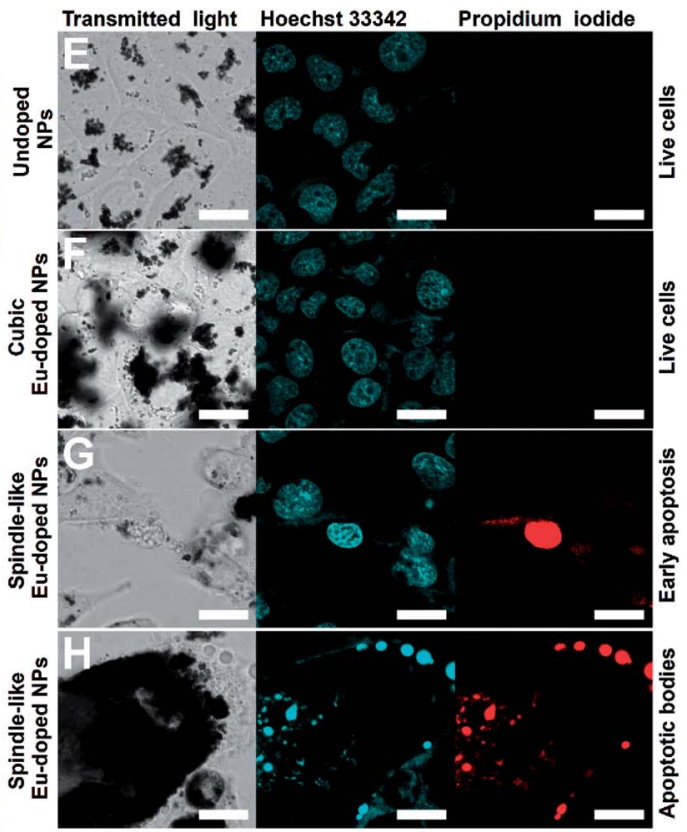

Fig. 7 Optical images of incubated with NPs CHO cells. (A-C) Collected using DIC microscopy images; (D) acquired via fluorescence microscopy image; $(E-H)$ acquired via laser scanning fluorescence microscopy images. In all experiments cells were incubated with nanoparticles for $48 \mathrm{~h}$. In images A, B, and C cells were incubated with undoped NPs, Eu-doped cubic NPs, and Eu-doped spindle-like NPs respectively. Image D shows fluorescence of Hoechst-stained cells from image $C$. Images $(E-H)$ demonstrate cells incubated with undoped NPs (E), Eu-doped cubic NPs (F), and Eu-doped spindle-like NPs (G and H), stained with Hoechst and PI dyes. The scale bar is $20 \mu \mathrm{m}$. 
as SEM and optical microscopy. SEM study showed that the CHO cells after treatment with the spindle-like NPs were damaged (Fig. 6B and $\mathrm{S} 1 \dagger$ ). The destruction of the cell membrane was shown, and the fibrillar components of the cytoskeleton, and membrane organelles were visible. To observe interactions between the NPs and living cells, the differential interference contrast (Fig. 7A-C) and fluorescent microscopy (Fig. 7D) were used. Fig. 7C and D clearly show that the nanoparticles did not penetrate into the cell nuclei. Additionally, the cells treated with NPs for $48 \mathrm{~h}$ were stained with Hoechst and PI (cell-impermeable DNA dye, stains DNA if cell membrane is permeabilized) to visualize live, necrotic and apoptotic cells. Laser scanning confocal microscopy (Fig. 7E-H) showed that treatment with undoped iron oxide NPs and cubic europiumdoped NPs did not cause any observable signs of apoptosis and necrosis (Fig. 7E and F). The Hoechst staining showed that cells had round-shaped and evenly-stained nuclei. Moreover, the PI-stained cells were not found; this observation is in an agreement with the fact that live cells have a non-permeabilized membrane. On the other hand, the fragmented and PI-stained nuclei (Fig. 7G) and apoptotic bodies (Fig. 7H) were observed in the cells treated with spindle-like europium-doped NPs. ${ }^{\mathbf{4 6}}$

To investigate this behavior in a quantitative manner, we examined the NPs-associated effects on cells with imaging flow cytometry analysis. ${ }^{58}$ FITC-labeled Annexin V and PI were used to identify live, apoptotic and necrotic cells. Annexin V binds to phosphatidylserine that translocates to the external leaflet of the plasma membrane during apoptosis. PI is a membraneimpermeable nucleic acid intercalator: early apoptotic cells exclude PI, while late apoptotic, and necrotic cells stain positively. The dot plot for cells after $48 \mathrm{~h}$ incubation with the spindlelike europium-doped NPs indicated that less than $5 \%$ of the cells were alive (Fig. 8), while in other samples the populations of living cells were approximately between $70 \%$ and $90 \%$. Thus, the experiments have confirmed that the spindle-like NPs doped with europium have a pronounced cytotoxic effect and cause early apoptosis (ca. 57\%) and late apoptosis/necrosis (ca. 39\%) of cells.

The paramagnetic nature of the obtained particles was verified by the magnetic particle quantification (MPQ) technique, ${ }^{\mathbf{4 7}}$ which showed no presence of ferro- and superparamagnetic fractions at the level of $0.1 \mathrm{ng} \mathrm{mL}^{-1}$. In vivo evaluation of the MRIcontrasting properties of the NPs was performed in an animal model using the tomography scanner. The NPs were coated with CMD to ensure colloidal stability of the NPs. Each animal was scanned in various modes with the different TR (repetition time duration between the corresponding consecutive points on a repeating series of pulses and echoes) and TE (echo time period between the middle of the first pulse to the middle of echo) parameters. The measurements were carried out using the FLASH (Fast Low Angle Shot) and the RARE (Rapid Acquisition with Refocused Echoes) sequences. For estimation of the contrasting properties of the NPs, we used intensities of the MRI signal in the liver area of the MRI images of test and control mice. To remove the error associated with the individual imaging
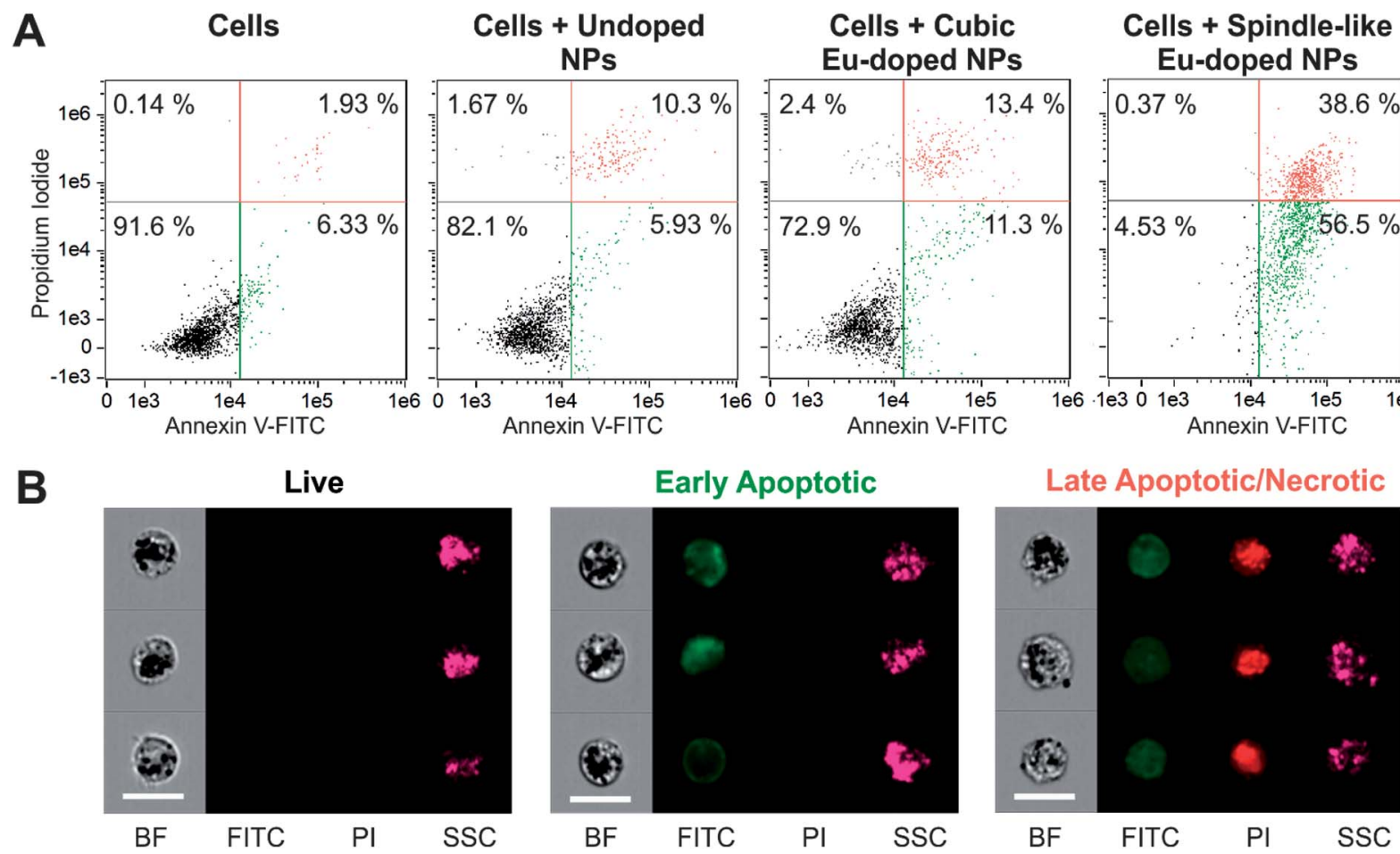

BF

FITC

PI SSC

BF

FITC

PI

SSC

BF

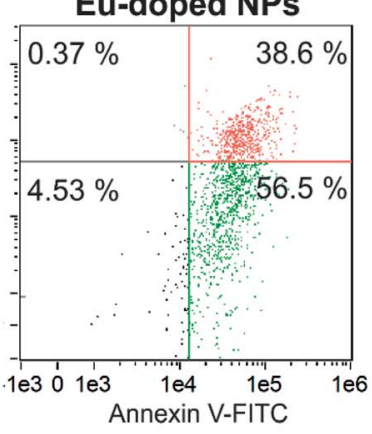

Fig. 8 Imaging flow cytometry analysis of seeded for 48 h CHO cells with different NPs. The cells were stained with PI and FITC-labeled annexin V (Annexin V-FITC). (A) Compensated dot plots of PI/Annexin V-FITC staining of the cells after the incubation with NPs. Lower left, lower right, and higher right areas include viable, early apoptotic, and late apoptotic/necrotic subpopulations, respectively. The numbers in areas demonstrate the share of the subpopulation in all collected cells. (B) Representative cell images from all subpopulations. The images are acquired in bright field (BF), FITC-sensitive, PI-sensitive, and side scatter (SSC) channels. The scale bar is $20 \mu \mathrm{m}$. 
parameters and peculiarities of the animal under test, all the measured MRI signal intensities were compared to the averaged intensity of the muscle tissue signal, which was almost independent of the NPs presence. The contrast factor was calculated as $K=I_{\text {muscle }} / I_{\text {liver }}$, where $I_{\text {muscle }}$ and $I_{\text {liver }}$ were intensities of the MRI signals from muscle and liver areas in the mouse, respectively. Because of the bigger $I$ the brighter the chosen area, the bigger $K$ (Table $\mathrm{S} 1 \dagger$ ) indicate the more pronounced negative contrast of NPs. Fig. 9A and Table S1† illustrate that the NPs doped with europium and undoped iron oxide NPs offer MRI contrasting properties in FLASH and RARE (Fig. S2 $\dagger$ ) modes of scanning. Negative contrasting properties of europium-doped NPs were also supported by higher values of both $r_{1}$ and $r_{2}$ relaxivities (Fig. 9B). Also, the europium-doped NPs are more susceptible to the field (Fig. 9C); the magnetization curves are typical for nano- and microsized hematite. ${ }^{\mathbf{4 8 4} 9}$ The changes of the magnetic properties caused by lanthanide doping is often observed for the iron oxide NPs of different composition and size. The primary use of such phenomenon is enhancement of the contrasting properties of NPs. ${ }^{50-53}$

As can be seen from Fig. 9A the nanoparticles are negative MRI contrast agents, concentrating in the liver and spleen. The ICP-MS analysis (Fig. 10) of acid-digested mice organs has shown that NPs concentration in liver and spleen exceeds by at least an order of magnitude that in the rest tissues. In addition, the leaky endothelial wall in liver, spleen, and bone marrow leads to the
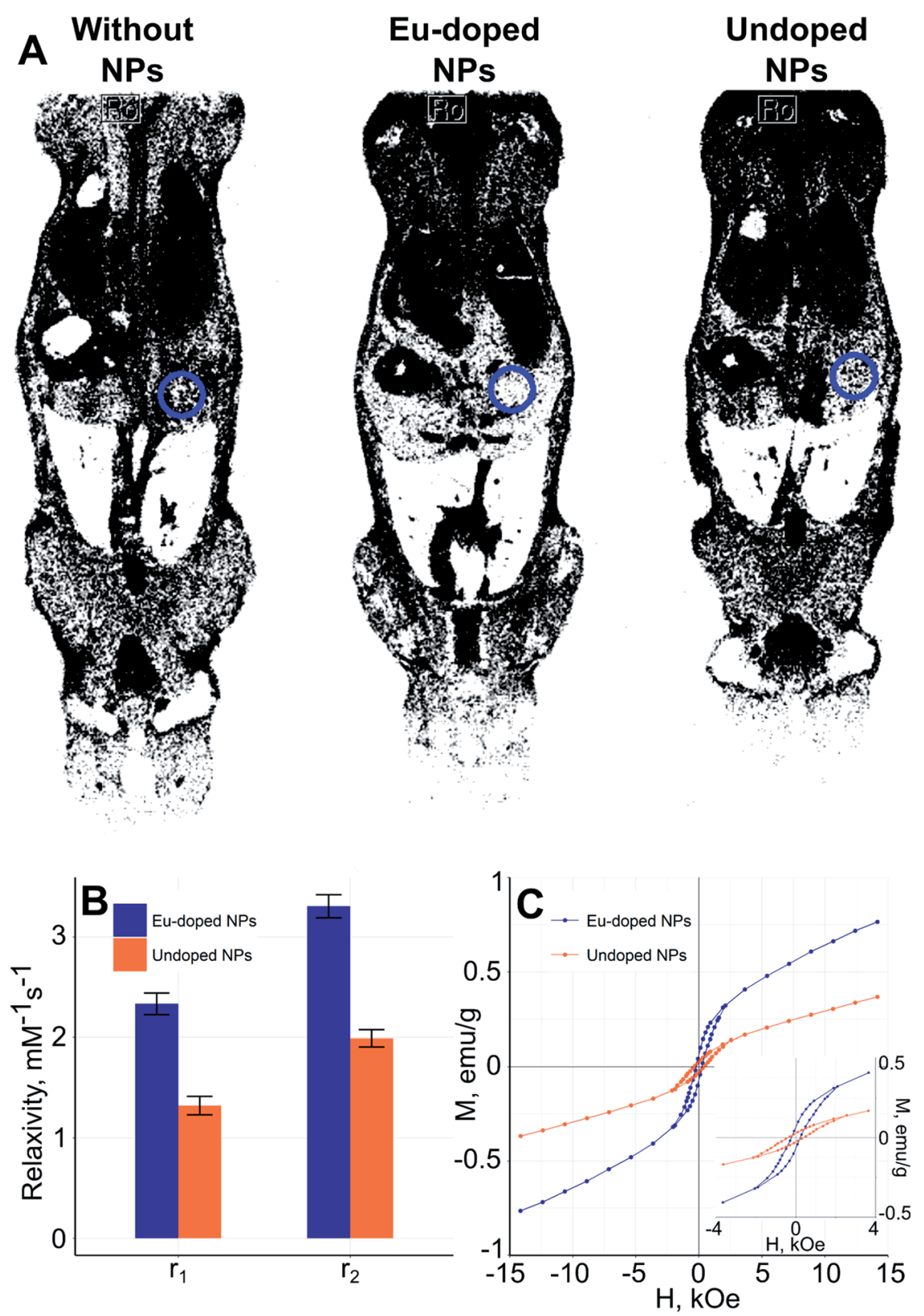

Fig. 9 Inverted MRI images of mice and magnetic properties of the NPs. (A) Images of injected and noninjected mice (RARE sequence), repetition time $=300 \mathrm{~ms}$, echo time $=10 \mathrm{~ms}$, circles indicate contrasted liver regions; (B) relaxivities of the NPs at RT (measured at external field of $0.23 \mathrm{~T}$ ), (C) magnetization curves of the NPs at RT. 


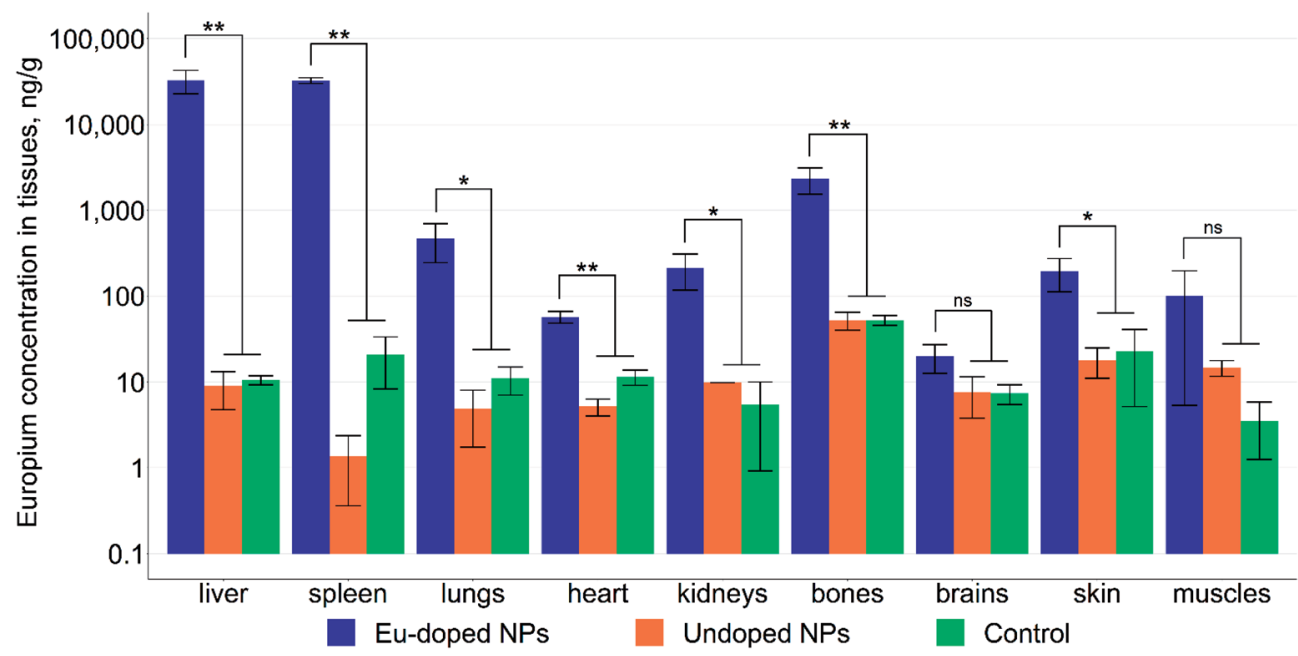

Fig. 10 Concentration of europium in mice organs according to ICP-MS. Statistical significance was determined using ANOVA with Tukey's post-hoc test. The data are presented as mean \pm standard deviation ( $n=3$ per group).

maximization of NPs concentration in the corresponding organs; this fact allows us to conclude that the NPs could accumulate in a solid tumor due to the "enhanced permeability and retention" (EPR) effect. ${ }^{54}$ Additionally, the analysis revealed that more than $98 \%$ of the NPs were indeed accumulated in liver $(78.4 \%)$ and spleen $(20.4 \%)$. This finding is in accordance with the fact that the iron oxide nanoparticles of size between $10 \mathrm{~nm}$ and $100 \mathrm{~nm}$ are cleared from the bloodstream by the mononuclear phagocyte system (MPS) mostly located in liver and spleen. ${ }^{55}$

For additional evaluation of the cytotoxic properties of NPs, we have studied the biochemical parameters in serum $2 \mathrm{~h}$ after injection of $1 \mathrm{mg}$ of the NPs (Table S2†). The liver damage was evaluated by the levels of alanine aminotransferase (ALT), aspartate aminotransferase (AST) and bilirubin (BIL). The nephrotoxicity was determined by creatinine (CT), and the heart damage - by lactate dehydrogenase (LDH) enzyme. We observed a decrease in the level of AST and BIL in the case of europium-doped nanoparticles, and a growth in the level of ALT in the group injected with the undoped iron oxide NPs. At the same time, kidneys and heart were not significantly affected. Although all enzymes were in the normal clinical range, this study showed that nanoparticles make a greater impact on the liver than the other organs.

\section{Conclusions}

We have demonstrated a novel facile method for preparation of the europium-doped iron oxide nanoparticles. According to the MTT test, imaging flow cytometry, optical and electron microscopy, the NPs possess high cytotoxicity, which, in spite of low europium content, is due not only to the influence of heavy metal but also to the shape of the NPs. Therefore, this is an example of cytotoxic NPs with low heavy metal content. Various iron oxide particles are already approved in the clinic for MRI-contrasting and iron deficiency anemia treatment. The development of our Eu-doped NPs is highly beneficial because they have both MRIimaging and cytotoxic modalities. This allows early efficient evaluation of NPs-based therapy by facile noninvasive measurement of NPs delivery to tumors. Therefore, the NPs are promising as cytotoxic and MRI-contrasting components for development of novel nanoagents for theranostic applications.

\section{Conflicts of interest}

There are no conflicts to declare.

\section{Acknowledgements}

The reported study was funded by the Russian Science Foundation Grant \#18-73-10102 (synthesis, biofunctionalization, characterization of the multimodal MRI active/cytotoxic nanoparticles, studies of particle-cell interactions in vitro, MRI investigation of in vivo behavior of the nanoagents) and by Russian Foundation for Basic Research Grant \#18-34-00834 (ICP-MS biodistribution study). We would like to thank Andrey V. Babenyshev for SEM analysis, Dr Artem A. Sizikov for help with XRD analysis, Dr Alexander M. Perepukhov for help with the relaxivity measurements, Dr Anna A. Lizunova for the TEM-EDX mapping analysis, and Dr Dmitriy Yu. Karpenkov for the magnetization measurements.

\section{Notes and references}

1 R.-V. Kalaydina, K. Bajwa, B. Qorri, A. DeCarlo and M. R. Szewczuk, Int. J. Nanomed., 2018, 13, 4727-4745.

2 I. L. Sokolov, V. R. Cherkasov, A. A. Tregubov, S. R. Buiucli and M. P. Nikitin, Biochim. Biophys. Acta - Gen. Subj., 2017, 1861(6), 1530-1544.

3 A. A. Tregubov, P. I. Nikitin and M. P. Nikitin, Chem. Rev., 2018, 118, 10294-10348.

4 M. Liong, J. Lu, M. Kovochich, T. Xia, S. G. Ruehm, A. E. Nel, F. Tamanoi and J. I. Zink, ACS Nano, 2008, 2, 889-896.

5 M. P. Nikitin, V. O. Shipunova, S. M. Deyev and P. I. Nikitin, Nat. Nanotechnol., 2014, 9, 716-722. 
6 E. Huynh and G. Zheng, WIREs Nanomed Nanobiotechnol, 2013, 5, 250-265.

7 J. Xiao, T. Peng, R. Li, Z. Peng and C. Yan, J. Solid State Chem., 2006, 179, 1161-1170.

8 P. M. Aneesh, K. M. Krishna and M. K. Jayaraj, J. Electrochem. Soc., 2009, 156, 33-36.

9 B. Pal and P. K. Giri, J. Appl. Phys., 2010, 108, 84322.

10 W. Li, Y. Wang, H. Lin, S. I. Shah, C. P. Huang, D. J. Doren, S. A. Rykov, J. G. Chen and M. A. Barteau, Appl. Phys. Lett., 2003, 83, 4143-4145.

11 A. K. Gupta and M. Gupta, Biomaterials, 2005, 26, 3995-4021.

12 S. Laurent, D. Forge, M. Port, A. Roch, C. Robic, L. Vander Elst and R. N. Muller, Chem. Rev., 2008, 108, 2064-2110.

13 W. Wu, Z. Wu, T. Yu, C. Jiang and W.-S. Kim, Sci. Technol. Adv. Mater., 2015, 16, 23501.

14 A. P. Davis and V. Bhatnagar, Chemosphere, 1995, 30, 243-256. 15 Y. Mamindy-Pajany, C. Hurel, N. Marmier and M. Roméo, Comptes Rendus Chim, 2009, 12, 876-881.

16 L. S. Balistrieri and J. W. Murray, Geochim. Cosmochim. Acta, 1982, 46, 1253-1265.

17 J. Antelo, M. Avena, S. Fiol, R. López and F. Arce, J. Colloid Interface Sci., 2005, 285, 476-486.

18 V. A. Grover, J. Hu, K. E. Engates and H. J. Shipley, Environ. Toxicol. Chem., 2012, 31, 86-92.

19 H. I. Adegoke, F. AmooAdekola, O. S. Fatoki and B. J. Ximba, Korean J. Chem. Eng., 2014, 31, 142-154.

20 N. Marmier, J. Dumonceau and F. Fromage, J. Contam. Hydrol., 1997, 26, 159-167.

21 L. J. Glover, M. J. Eick and P. V Brady, Soil Sci. Soc. Am. J., 2002, 66, 797.

22 A. V. Lunin, E. L. Kolychev, E. N. Mochalova, V. R. Cherkasov and M. P. Nikitin, J. Colloid Interface Sci., 2019, 541, 143-149.

23 H. Wan, P. Rong, X. Liu, L. Yang, Y. Jiang, N. Zhang, R. Ma, S. Liang, H. Wang and G. Qiu, Adv. Funct. Mater., 2017, 27, 1606821.

24 J. Xi, J. H. Lan, G. W. Lu, Y. L. Zhao, Z. F. Chai and W. Q. Shi, Mol. Simul., 2014, 40, 379-386.

25 A. Zoppi, C. Lofrumento, E. M. Castellucci and P. Sciau, J. Raman Spectrosc., 2008, 39, 40-46.

26 F. Denizot and R. Lang, J. Immunol. Methods, 1986, 89, 271-277.

27 J. van Meerloo, G. J. L. Kaspers and J. Cloos, in Cancer Cell Culture: Methods and Protocols, ed. I. A. Cree, Humana Press, Totowa, NJ, 2011, pp. 237-245.

28 X.-Y. Sun, J.-M. Ouyang and K. Yu, Sci. Rep., 2017, 7, 7250.

29 J. H. Lee, J. E. Ju, B. Il Kim, P. J. Pak, E.-K. Choi, H.-S. Lee and N. Chung, Environ. Toxicol. Chem., 2014, 33, 2759-2766.

30 C. Kinnear, T. L. Moore, L. Rodriguez-Lorenzo, B. RothenRutishauser and A. Petri-Fink, Chem. Rev., 2017, 117, 11476-11521.

31 Z. Wang, D. Xie, H. Liu, Z. Bao and Y. Wang, RSC Adv, 2016, 6, 33009-33013.

32 W. Di, J. Li, N. Shirahata, Y. Sakka, M.-G. Willinger and N. Pinna, Nanoscale, 2011, 3, 1263-1269.

33 F. Chen, Y.-J. Zhu, K.-H. Zhang, J. Wu, K.-W. Wang, Q.-L. Tang and X.-M. Mo, Nanoscale Res. Lett., 2011, 6, 67.

34 P. Gangwar, D. Bhattacharyya, V. Mahalingam, S. Sivakumar and C. Hazra, Sci. Adv. Mater., 2012, 4, 656-662.
35 P. E. Petrochenko, Q. Zhang, H. Wang, T. Sun, B. Wildt, M. W. Betz, P. L. Goering and R. J. Narayan, Int. J. Appl. Ceram. Technol., 2012, 9, 881-892.

36 C. Zhou, H. Wu, C. Huang, M. Wang and N. Jia, Part. Part. Syst. Charact., 2014, 31, 675-684.

37 N. O. Nuñez, M. García, J. García-Sevillano, S. RiveraFernández, J. M. de la Fuente and M. Ocaña, Eur. J. Inorg. Chem., 2014, 2014, 6075-6084.

38 J. Gómez-Morales, C. Verdugo-Escamilla, R. FernándezPenas, C. M. Parra-Milla, C. Drouet, F. Maube-Bosc, F. Oltolina, M. Prat and J. F. Fernández-Sánchez, RSC Adv, 2018, 8, 2385-2397.

39 A. A. Ansari, A. Khan, J. P. Labis, M. Alam, M. Aslam Manthrammel, M. Ahamed, M. J. Akhtar, A. Aldalbahi and H. Ghaithan, Mater. Sci. Eng. C, 2019, 96, 365-373.

40 V. S. Bollu, S. K. Nethi, R. K. Dasari, S. S. N. Rao, S. Misra and C. R. Patra, Nanotoxicology, 2016, 10, 413-425.

41 W. Di, J. Li, N. Shirahata, Y. Sakka, M. G. Willinger and N. Pinna, Nanoscale, 2011, 3, 1263-1269.

42 Y. Z. Zhao, J. Zhu, S. H. Zhu, Y. Y. Huang, Z. Y. Li and K. C. Zhou, Trans. Nonferrous Met. Soc. China, 2011, 21, 1773-1778.

43 K. Ge, W. Sun, S. Zhang, S. Wang, G. Jia, C. Zhang and J. Zhang, RSC Adv, 2016, 6, 21725-21734.

44 E. B. Kim, J. M. Seo, G. W. Kim, S. Y. Lee and T. J. Park, Enzyme Microb. Technol., 2016, 95, 201-208.

45 S. Chen, C. Zhang, G. Jia, J. Duan, S. Wang and J. Zhang, Mater. Sci. Eng. C, 2014, 43, 330-342.

46 L. C. Crowley, B. J. Marfell and N. J. Waterhouse, Cold Spring Harb. Protoc., 2016, 2016, 778-781.

47 P. I. Nikitin, P. M. Vetoshko and T. I. Ksenevich, Sens. Lett, 2007, 5, 296-299.

48 T. K. Van, H. G. Cha, C. K. Nguyen, S. W. Kim, M. H. Jung and Y. S. Kang, Cryst. Growth Des., 2012, 12, 862-868.

49 R. N. Bhowmik and A. Saravanan, J. Appl. Phys., 2010, 107, 053916.

50 T. S. Atabaev, Bionanoscience, 2018, 8, 299-303.

51 N. Xiao, W. Gu, H. Wang, Y. Deng, X. Shi and L. Ye, J. Colloid Interface Sci., 2014, 417, 159-165.

52 J. C. Park, G. T. Lee, H. K. Kim, B. Sung, Y. Lee, M. Kim, Y. Chang and J. H. Seo, ACS Appl. Mater. Interfaces, 2018, 10, 25080-25089.

53 L. Yang, Z. Zhou, H. Liu, C. Wu, H. Zhang, G. Huang, H. Ai and J. Gao, Nanoscale, 2015, 7, 6843-6850.

54 K. Raza, P. Kumar, N. Kumar and R. Malik, Adv. Nanomedicine Deliv. Ther. Nucleic Acids, 2017, 166-186.

55 H. Arami, A. Khandhar, D. Liggitt and K. M. Krishnan, Chem. Soc. Rev., 2015, 44, 8576-8607.

56 V. R. Cherkasov, E. N. Mochalova, A. V. Babenyshev, A. V. Vasilyeva, P. I. Nikitin and M. P. Nikitin, ACS Nano, 2020, DOI: 10.1021 /acsnano.9b07569.

57 V. R. Cherkasov, E. N. Mochalova, A. V. Babenyshev, J. M. Rozenberg, I. L. Sokolov and M. P. Nikitin, Acta Biomater., 2020, 103, 223-236.

58 E. N. Mochalova, I. A. Kotov, J. M. Rozenberg and M. P. Nikitin, Cytometry, 2020, DOI: 10.1002/cyto.a.23939. 